\title{
Genotypic variation of Agrobacterium-mediated transformation of Italian ryegrass
}

\author{
Ki-Won Lee \\ Grassland and Forages Division \\ National Institute of Animal Science \\ Rural Development Administration \\ Cheonan, Chungnam, 330-801, South Korea

\section{Gi Jun Choi} \\ Grassland and Forages Division \\ National Institute of Animal Science \\ Rural Development Administration \\ Cheonan, Chungnam, 330-801, South Korea

\section{Ki-Yong Kim} \\ Grassland and Forages Division \\ National Institute of Animal Science \\ Rural Development Administration \\ Cheonan, Chungnam, 330-801, South Korea

\section{Sei Hyung Yoon} \\ Grassland and Forages Division \\ National Institute of Animal Science \\ Rural Development Administration \\ Cheonan, Chungnam, 330-801, South Korea

\section{Hee Chung Ji} \\ Grassland and Forages Division \\ National Institute of Animal Science \\ Rural Development Administration \\ Cheonan, Chungnam, 330-801, South Korea

\section{Hyung Soo Park} \\ Grassland and Forages Division \\ National Institute of Animal Science \\ Rural Development Administration \\ Cheonan, Chungnam, 330-801, South Korea

\section{Young Chul Lim} \\ Grassland and Forages Division \\ National Institute of Animal Science \\ Rural Development Administration \\ Cheonan, Chungnam, 330-801, South Korea

\section{Sang-Hoon Lee*} \\ Grassland and Forages Division \\ National Institute of Animal Science \\ Rural Development Administration \\ Cheonan, Chungnam, 330-801, South Korea \\ E-mail: sanghoon@korea.kr
}

Financial support: This work was supported by grants from the National Institute of Animal Science (Project no. 200901OFT082558123) and the BioGreen 21 Program (Project no. 20070301-034-015), Rural Development Administration (RDA), Korea.

Keywords: Agrobacterium, forage crop, Italian ryegrass, transgenic plants.

Abbreviations: BA: 6-benzyladenine

GUS: $\beta$-glucuronidase

*Corresponding author 
HPT: hygromycin phosphotransferase

$\mathrm{X}$-gluc: 5-bromo-4-chloro-3-indolyl-b-glucuronide
In the present study, genotypic variation of Agrobacterium-mediated transformation of Korean Italian ryegrass has been evaluated. Mature seedderived calli of seven cultivars were inoculated and cocultured with Agrobacterium tumefaciens carrying the binary vector pCAMBIA1301, which contains a reporter gene (gus) and a plant selectable marker gene conferring resistance to hygromycin (hpt) in the T-DNA region. The effects of several factors such as callus type and callus age on transformation effectiveness and the expression of the GUS gene were investigated. The highest transformation effectiveness (6.7\%) was obtained with the Hwasan 101 cultivar when 9-week-old calli (type-I) were inoculated with Agrobacterium. The overall transformation rates of the examined cultivars ranged from $0.4 \%$ to $6.7 \%$. GUS histochemical assays, PCR, and southern analysis of transgenic plants demonstrated that transgenes were successfully integrated into the genome of Italian ryegrass. Thus, evaluation of transformation effectiveness and selection of a suitable cultivar of Italian ryegrass may improve molecular breeding of this species.

The plant genetic transformation system is one of the most crucial technologies in plant molecular breeding. A transgenic approach to genetic improvement of traditional Italian ryegrass (Lolium multiflorum Lam) cultivars would promote desirable traits such as disease, insect, and pest resistance, tolerance to several abiotic stresses, forage quality, and production efficiency (Ye et al. 1997). Italian ryegrass is one of the fastest growing forage grass species, and it provides an excellent high quality feed for most classes of livestock. It is regarded as a versatile grass species that can be used for pasture, hay, green chop or silage (Hides et al. 1993; Isselstein et al. 1993), and it is widely used for forage. Improvement of the cold tolerance of Italian ryegrass is an important breeding objective for enlargement of the cultivation area in Korea (Choi et al. 2008).

The susceptibility of Italian ryegrass to gene manipulation has been well established by direct gene transfer methods such as particle bombardment (Ye et al. 1997; Dalton et al. 1999; Takahashi et al. 2002) or by silicon-carbide fibermediated transformation (Dalton et al. 1998). For the first time, Ye et al. (1997) generated transgenic Italian ryegrass using embryogenic suspension cells as target for particle bombardment-mediated transformation system. Transformed Italian ryegrass expressing kanamycinresistant and $\beta$-glucuronidase gene have also been obtained using microprojectile bombardment wherein protoplasts were used as target cells. Although these studies generated higher number of transgenic Italian ryegrass; unfortunately, cultivars from which transgenic plants were regenerated were not mentioned. Dalton et al. (1998) also produced transgenic Italian ryegrass using silicon-carbide-fibermediated transformation system which is considered as simpler and less expensive comparative to microprojectile bombardment, however; in terms of efficiency of resources the microprojectile bombardment method is preferable since larger volume of cells can be treated at one time (Dalton et al. 1998; Dalton et al. 1999). Although direct gene transfer technology has been used successfully to produce transgenic Italian ryegrass, it has been claimed in several studies that transgenic plants obtained by direct gene transfer methods through protoplast or particle bombardment showed multiple copy insertions of the transgenes (Dalton et al. 1995; Spangenberg et al. 1995). In addition, it has been hypothesized that transgenic plants obtained from particle bombardment might be an increased rate of truncated transgene insertations and/or transgene silencing, probably as a consequence of DNA fragmentation during particle coating and penetration into the target cells (Gao et al. 2008). Moreover, protoplast and cell suspension cultures used for direct gene transformation system involved laborious steps and have been difficult to reproduce in terms of initiation of and maintenance of cell suspension cultures, and also in isolation of protoplast. Recently Gao et al. (2008) revealed that transgene expression in transgenic plants was quite higher $(53 \%)$ in Agrobacterium-mediated transformation than that of the particle bombardment method (23\%), suggested that for efficient production of transgenic plants with stable and predictable transgene expression, Agrobacterium-mediated method offers considerable advantages over particle bombardment.

Agrobacterium-mediation of genetic transformation systems is a commonly used technique for genetic improvement. Advantages of Agrobacterium-mediation of genetic transformation, including the ability to transfer large pieces of DNA with minimal rearrangement, low experimental costs, and integration of relatively low numbers of transgene copies, have been described elsewhere (Hiei et al. 1994). To the best our knowledge, there have only been a few reports regarding Agrobacterium-mediated transformation (Bettany et al. 2003), which recovered a total of eight transgenic plants wherein only one showed GUS expression. In addition, up to now, there was no comparative evaluation of the responses of Italian ryegrass cultivars in Agrobacteriummediated transformation system. A wide range of factors, however, such as plant genotype, explants type and age, cocultivation media and period, can influence the gene transfer efficiency from Agrobacterium to plant cells (Uranbey et al. 2005; Ahsan et al. 2007). Although, Agrobacterium-mediated transformation in Italian ryegrass was introduced in 2003 (Bettany et al. 2003), it still does 


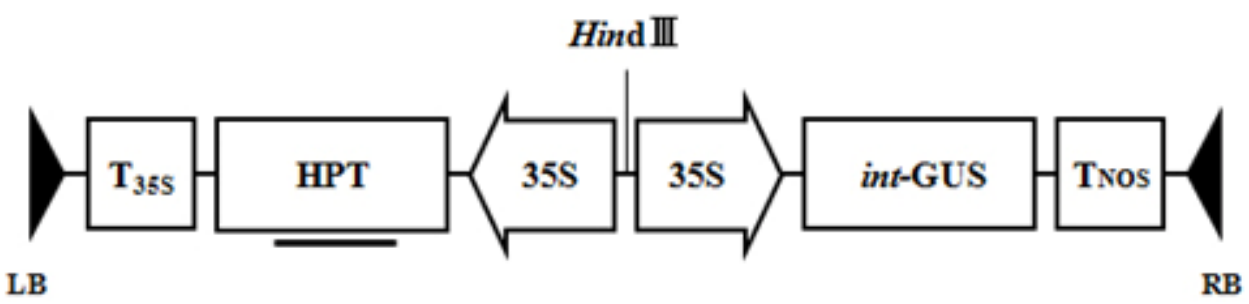

Figure 1. Plasmid construction of the pCAMBIA1301 binary vector used for transformation of Italian ryegrass plants. HPT, hygromycin phosphotransferase; int-GUS, $\beta$-glucuronidase containing intron; 35S, cauliflower mosaic virus 35S promoter; T35S, polyA cauliflower mosaic virus $35 \mathrm{~S}$ terminator; TNOS, polyA nopaline synthase terminator; Bold bar indicates the region amplified by PCR. LB andRB indicates leaf and right border, respectively.

not yield consistent results in respect of genotypic response and transformation frequency. The absence of highly efficient genotype independent regeneration and transformation systems is a major obstacle to the application of gene transfer technology to economically important Italian ryegrass cultivars. Therefore, a simple, reproducible, and genotype independent efficient transformation method is still a basic demand for largescale transgenic Italian ryegrass production.

Currently, the importance of forage grass transformation is increasing as a means of introducing better and more useful traits into many cultivars of economic relevance for integrated forage grass management (Takahashi et al. 2005; Wu et al. 2005; Lee et al. 2007; Zhao et al. 2007). Genetic transformation may be an important contribution to the improvement of forage grasses. However, the efficiency with which Italian ryegrass cultivars are transformed is very low (Bettany et al. 2003). In this study, we have reported an improved transformation protocol for seven cultivars of Korean Italian ryegrass by use of mature seed-derived calli as explants.

\section{MATERIALS AND METHODS}

\section{Explant preparation and culture conditions}

Italian ryegrass seeds were obtained from the Grassland and Forages Research Center, National Institute of Animal Science, Rural Development Administration, Korea. Mature seeds of seven cultivars of Korean Italian ryegrass (Lolium multiflorum Lam.), namely, Kogreen, Kospeed, Kowinearly, Kowinmaster, Hwasan 101, Hwasan 104 and Kowinner, were dehusked by stirring in $50 \%$ sulfuric acid for $20 \mathrm{~min}$ and rinsing with sterile water. Dehusked seeds were then surface-sterilized with $70 \%$ ethanol for $1 \mathrm{~min}$ and $30 \%$ bleach (5.25\% sodium hypochlorite) for $30 \mathrm{~min}$ with gentle shaking, followed by three washes with sterile water. Finally, they were blotted with sterile Whatman filter paper.

The surface-sterilized seeds were placed in MS (Murashige and Skoog, 1962) medium containing $5 \mathrm{mg} / \mathrm{L} 2,4$ dichlorophenoxyacetic acid (2,4-D), $0.5 \mathrm{mg} / \mathrm{L} \quad 6-$ benzylaminopurine (BA), $500 \mathrm{mg} / \mathrm{L}$ L-proline, $1 \mathrm{mg} / \mathrm{L}$ casein hydrolysate, $30 \mathrm{~g} / \mathrm{L}$ sucrose, and $3 \mathrm{~g} / \mathrm{L}$ Gelrite. The cultures were transferred to controlled growth chambers at $24 \pm 2^{\circ} \mathrm{C}$ for three weeks in the dark. After three weeks, calluses were removed from the germinating shoots and divided into 4-6 mm-diameter pieces and sub-cultured every three weeks on the same fresh medium, and then the calli were used for transformation.

\section{Plant transformation}

In the transformation experiments, Agrobacterium tumefaciens strain EHA105 containing the binary plasmid pCAMBIA1301 (Center for the Application of Molecular Biology to the International Agriculture of Canberra, Australia) was used. The plasmid contains a reporter gene (gus) and a plant selectable marker gene conferring resistance to hygromycin (hpt), both driven by the CaMV $35 \mathrm{~S}$ promoter (Figure 1). A single colony of bacteria was inoculated on liquid YEP medium containing $100 \mathrm{mg} / \mathrm{L}$ kanamycin and incubated in a shaker $(200 \mathrm{rpm})$ at $28^{\circ} \mathrm{C}$ overnight. Afterwards, the culture was centrifuged at 2,500 $g$ for $10 \mathrm{~min}$, and the pellet was resuspended in MS medium supplemented with $30 \mathrm{~g} / \mathrm{L}$ sucrose, $10 \mathrm{~g} / \mathrm{L}$ glucose, and $40 \mathrm{mg} / \mathrm{L}$ L-cysteine with $200 \mu \mathrm{M}$ acetosyringone. Embryonic calli (90 pieces) were immersed in the bacterial suspension with gentle shaking for $60 \mathrm{~min}$, and the excess bacterial suspension was removed by blotting on sterile tissue paper. Inoculated calli were transferred onto a coculture medium for five days in the dark in MS with $3 \mathrm{mg} / \mathrm{L}$ 2,4-D, $0.5 \mathrm{mg} / \mathrm{L} \mathrm{BA}, 1 \mathrm{~g} / \mathrm{L}$ casein hydrolysate, $500 \mathrm{mg} / \mathrm{L} \mathrm{L}-$ proline, $40 \mathrm{mg} / \mathrm{L}$ L-cysteine, $30 \mathrm{~g} / \mathrm{L}$ sucrose, $200 \mu \mathrm{M}$ acetosyringone, and $2 \mathrm{~g} / \mathrm{L}$ Gelrite.

\section{Selection and regeneration of transgenic plants}

Five days after co-culture, the explants were washed in 500 $\mathrm{mg} / \mathrm{L}$ cefotaxime to kill the surface Agrobacteria, and then co-cultivated calli were subcultured on the selection medium, which is MS medium supplemented with $1 \mathrm{mg} / \mathrm{L}$ 2,4-D, $5 \mathrm{mg} / \mathrm{L} \mathrm{BA}, 1 \mathrm{~g} / \mathrm{L}$ casein hydrolysate, $500 \mathrm{mg} / \mathrm{L} \mathrm{L}-$ proline, $40 \mathrm{mg} / \mathrm{L}$ L-cysteine, $30 \mathrm{~g} / \mathrm{L}$ sucrose, $3 \mathrm{~g} / \mathrm{L}$ Gelrite, $250 \mathrm{mg} / \mathrm{L}$ cefotaxime, and $50 \mathrm{mg} / \mathrm{L}$ hygromycin. These calli were sub-cultured every 3 weeks onto fresh medium of the same composition at $25^{\circ} \mathrm{C}$ with a $16 \mathrm{hrs}$ light photoperiod $\left(100 \mu \mathrm{mol} \mathrm{m} \mathrm{m}^{-2} \mathrm{sec}^{-1}\right)$ until the development of plantlets. Finally, regenerated putative transgenic shoots 
Table 1. Callus induction from mature seeds of seven Italian ryegrass cultivars after 6 weeks of culture.

\begin{tabular}{|l|c|c|c|}
\hline \multirow{2}{*}{\multicolumn{1}{|c|}{ Cultivars }} & \multicolumn{3}{c|}{ Callus type of mature seed culture (\%) } \\
\cline { 2 - 4 } & Type-I* & Type-II** & Total \\
\hline Kogreen & $35.3 \pm 3.1$ & $27.7 \pm 3.5$ & $63.0 \pm 5.2$ \\
\hline Kospeed & $44.0 \pm 4.6$ & $30.0 \pm 2.0$ & $74.0 \pm 3.6$ \\
\hline Kowinearly & $46.0 \pm 8.6$ & $28.7 \pm 2.3$ & $74.7 \pm 9.3$ \\
\hline Kowinmaster & $30.7 \pm 3.8$ & $25.0 \pm 3.8$ & $55.7 \pm 3.8$ \\
\hline Hwasan 101 & $47.3 \pm 4.9$ & $33.3 \pm 4.2$ & $80.7 \pm 4.0$ \\
\hline Hwasan 104 & $25.0 \pm 10.8$ & $23.3 \pm 4.4$ & $48.3 \pm 12.7$ \\
\hline Kowinner & $29.0 \pm 4.6$ & $24.3 \pm 7.5$ & $53.3 \pm 3.2$ \\
\hline
\end{tabular}

${ }^{\text {aD } D a t a}$ were expressed as the average of three replicates, each with 100 mature seeds cultured on callus induction medium and each value is the mean of three individual experiments. Morphological phenotypes of embryogenic calli* and non-embryogenic calli**.

were separated and transferred onto rooting medium containing half strength MS medium supplemented with 30 $\mathrm{g} / \mathrm{L}$ sucrose, $2 \mathrm{~g} / \mathrm{L}$ Gelrite, $250 \mathrm{mg} / \mathrm{L}$ cefotaxime, and 50 $\mathrm{mg} / \mathrm{L}$ hygromycin. While, in the earlier study (Bettany et al. 2003), putative transgenic calli were selected with relatively higher concentration of hygromycin $(75 \mathrm{mg} / \mathrm{L})$, the present study we found that selection of putative transformant callus with higher than $50 \mathrm{mg} / \mathrm{L}$ hygromycin caused a severe inhibition of shoot regeneration from the Hm-resistant calli. In addition, it has been reported that continuous selection of low concentration of hygromycin produced higher number of transgenic plants without escape (Dalton et al. 1995). The transformation effectiveness of each cultivar was calculated as follows:

Total number of $\mathrm{Hm}^{\mathrm{R}}$ calli showing regeneration $\times 100$

Total number of calli inoculated in Agrobacterium-mediated transformation system

\section{Histochemical assay and measurement of the frequency of GUS}

Following co-cultivation, the explants were subjected to a transient GUS histochemical assay according to Jefferson et al. (1987). Five days after co-cultivation, calli were incubated for $12 \mathrm{hrs}$ at $37^{\circ} \mathrm{C}$ in the substrate X-gluc (5bromo, 4-chloro, 3-indolyl-glucuronide) and subsequently bleached with $70 \%$ ethanol for $24 \mathrm{hrs}$ to remove chlorophyll. Transient gus expression was measured after co-cultivation by counting the gus-positive calli appearing in blue zones (1 $\mathrm{mm}$ or more in diameter) as described previously (Lee et al. 2006), and each value is the mean of three individual experiments.

\section{Molecular analysis of transgenic plants}

Confirmation of stable integration of the transgene gene in to the putatively transgenic Korean Italian ryegrass genome
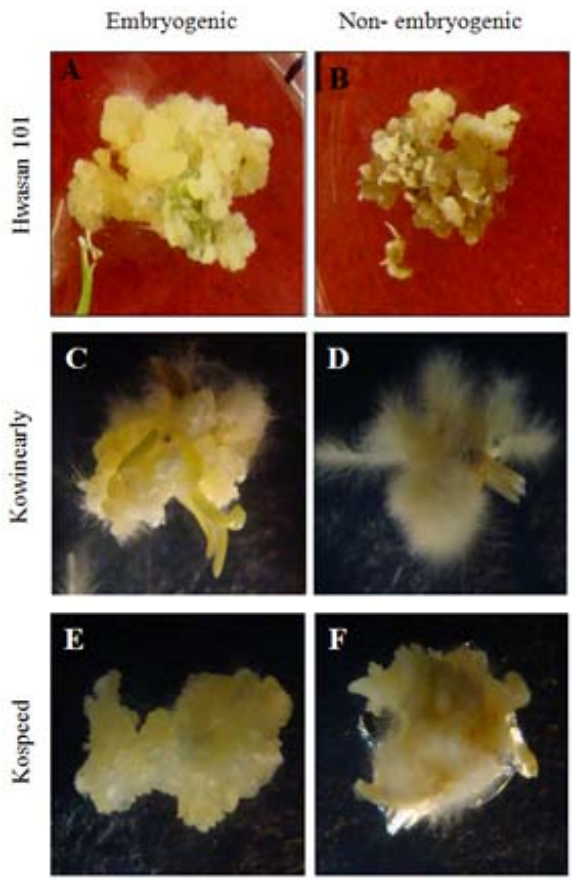

Figure 2. Different types of callus of Italian ryegrass. A, C and $E$ represents the embrygenic and $B, D$ and $F$ represents the non-embryogenic type of callus of Hwasan 101, Kowinearly and Kospeed cultivars, respectively. 
Table 2. Effect of callus age on GUS activity of Italian ryegrass cultivar Hwasan 101 after transformation in the co-cultivation medium.

\begin{tabular}{|c|c|c|c|c|}
\hline \multirow{2}{*}{ Age of callus (weeks) } & \multicolumn{4}{|c|}{ GUS + ${ }^{\mathrm{a}}$ calli (\%) } \\
\cline { 2 - 5 } & \multicolumn{3}{|c|}{ Experiment } & \multirow{2}{*}{ Mean \pm SE } \\
\cline { 2 - 5 } & 1 & 2 & 3 & $1.0 \pm 1.0$ \\
\hline 3 & 1 & 2 & 0 & $4.7 \pm 2.1$ \\
\hline 6 & 4 & 3 & 7 & $7.3 \pm 2.1$ \\
\hline 12 & 5 & 8 & 9 & $3.3 \pm 1.5$ \\
\hline
\end{tabular}

${ }^{a}$ Data were taken 5 days after Agrobacterium inoculation and means are from 30 calli per treatment and each value is the mean of three individual experiments.

was demonstrated by polymerase chain reaction (PCR) analysis. Genomic DNA was extracted from the leaves of putative transgenic plants and non-transformed (wild type) plants by the CTAB method (Murray and Thompson, 1980). The PCR were carried out by amplifying the coding region of transgene (hpt) using the following set of primer: 5'-CCTGAACTCACCGCGACG-3' (forward) and 5'AAGACCAATGCGGAGCAT AT-3' (reverse), which generate a $804 \mathrm{bp}$ fragment within the hpt gene. The PCR reaction was conducted as previously described (Lee et al. 2006), and PCR products were separated by electrophoresis on a $1 \%(\mathrm{w} / \mathrm{v})$ agarose gel. For Southern blot analysis, 20 $\mu \mathrm{g}$ of total genomic DNA was digested with HindIII and electrophoreted on a $1.0 \%(\mathrm{w} / \mathrm{v})$ agarose gel and blotted onto a nylon membrane (Nytran-Plus, Schleicher \& Schuell, Germany) according to the previously described method (Lee et al. 2006). To obtain a gene-specific probe for the gus gene, a $0.48-\mathrm{kb}$ fragment was amplified by PCR using pCAMBIA1301 as template and the previously described primers and conditions (Lee et al. 2006). The blot was subsequently analyzed by means of autoradiography with x-ray films (Kodak, Japan).

\section{RESULTS AND DISCUSSION}

We have investigated the cultivar-dependent Agrobacterium-mediated transformation effectiveness of Korean Italian ryegrass cultivars by evaluating several factors including callus type, cultivars and callus age. Transformation efficiency was determined by histochemical assays of GUS activity and hygromycin resistant regenerated plants.

\section{Effect of genotypes on callus type}

To examine the effect of genotype on the callus induction ability of Korean Italian ryegrass, seven cultivars were tested on callus induction medium. Calli appeared from mature seeds within 5-10 days on the callus induction medium. The primary callus induction frequency varied from 48.3 to $80.7 \%$ after a culture period of six weeks. In addition, a significant difference was found in the quality of calli induced among the seven Italian ryegrass cultivars (Table 1). For example, two types of calli, embryogenic (type-I) and non-embryogenic (type-II), were obtained. The embryogenic calli were relatively compact and whiteyellow in color (Figure 2). In contrast, non-embryogenic calli were watery and somewhat brown in color and sometimes contained hairy roots (Figure 2D and Figure 2F). Hwasan 101, Kowinearly and Kospeed showed high embryogenic callus induction ability (Table 1 and Figure 2). Three weeks after callus induction, embryogenic calli only were subcultured on the same fresh callus induction medium every three weeks.

Variations in callus induction ability among the tested cultivars indicated that these differences were completely dependent on genotype. Genotypic response to callus type and regeneration frequency in in vitro culture systems has frequently been observed in grass species (Bai and $\mathrm{Qu}$, 2000; Chaudhury and Qu, 2000).

\section{Effect of callus age on transformation}

Based on the results presented in Table 1, we have further optimized the effect of callus age in transformation frequency using the Hwasan 101 cultivar. Although, there was no significant differences observed in callus induction frequency of Kospeed, Kowinearly and Hwasan 101 cultivars; based on the highest induction frequency Hwasan 101 was selected. Three-week-old to 12 -week-old calli showed different GUS activity after 5 days co-cultivation. Results showed that transformation efficiency was greatly 

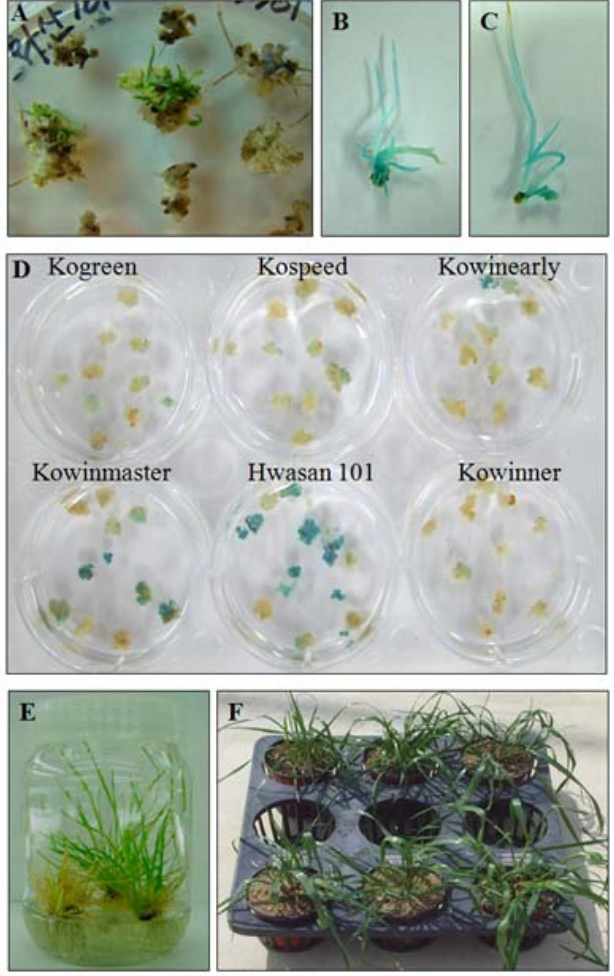

Figure 3. Regeneration of transgenic plants and histological GUS assay of putatively transgenic calli of seven Korean Italian ryegrass cultivars.

(A) Regeneration of putatively transformed plants of Hanswan 101 after 3 weeks culture on selection medium containing 50 $\mathrm{mg} / \mathrm{L}$ hygromycin.

(B) Histochemical GUS activity in leaf tissue in Hanswan 101 after 5 days co-culture with Agrobacterium.

(C) Histochemical GUS activity in leaf tissue in Korwinmaster after 5 days co-culture with Agrobacterium.

(D) Hygromycin-resistant calli showing GUS gene expression of seven Korean Italian ryegrass cultivars.

(E) Rooted transformants ready to be transferred to the greenhouse.

(F) Transgenic plants grown in pots in the green house.

influenced by callus age, wherein 9-week-old calli showed highest transformation efficiency in Hwasan 101 cultivar (Table 2). However, calli that was more than 9 weeks old turned brown and died after co-cultivation. While, the callus induction frequency of Kospeed and Kowinearly was very similar to Hwasan 101; therefore it could be expected that approximately 9 weeks old calli possibly the best explant for Korean Italian ryegrass cultivars in Agrobacterium-mediated genetic transformation system. Similarly, Dalton et al. (1999) noticed that young cell suspension cultures (i.e. less than 10 weeks after initiation) appeared to be critical for regeneration of transgenic Italian ryegrass in particle bombardment genetic transformation system. The effect of the age of explants on transgenosis and subsequent regeneration has been evaluated in many studies revealed that the response of young explants to transformation was better, however the comparatively middle aged (6-10 weeks) explants and/or cells responded better in both transformation and regeneration (de Kathen and Jacobsen, 1995; Nandakumar et al. 2004).

\section{Genotypic variation of Italian ryegrass cultivars on transformation effectiveness}

GUS expression was tested in the seven Korean Italian ryegrass cultivars transformed with the pCAMBIA1301 plasmid expressing the GUS reporter gene. Basal GUS expression of the pCAMBIA1301 construct with the CaMV 35S-promoter was observed in callus and leaf tissue (Figure $3)$. Transformed calli and leaves stained intensely with the substrate 5-bromo-4-chloro-3-indolyl glucuronide (x-gluc), while non-transformed calli and leaves did not (data not shown). The effect of cultivar on transformation effectiveness is summarized in Table 3. Transformation effectiveness ranged from 0.4 to $6.7 \%$. Cultivar Hwasan 101 showed relatively higher transformation effectiveness $(6.7 \%)$ than the other six cultivars. In contrast, cultivar Hwasan 104 showed the lowest transformation effectiveness, $0.4 \%$, compared to the other cultivars. Based on the results, it could be concluded that significant differences existed between the cultivars in transformation, and the Hwasan 101 cultivar could be considered the most suitable cultivar for Italian ryegrass transformation. Similar to our experiment, significant genotypic variation in Agrobacterium-mediated genetic transformation potential has been reported in many monocotyledonous species (Kumar et al. 2005; Wu et al. 2007).

\section{Molecular analysis of transgenic Italian ryegrass plants}

The putative $\mathrm{T}_{0}$ transformant plantlets were regenerated and further grown on rooting medium for 4 weeks. Hygromycin registrant calli showed regeneration of each cultivar is shown at Table 3. A total of 46 putative transgenic hygromycin resistant plantlets were recovered. Putatively transgenic plants obtained from each cultivar were used for PCR analysis using hpt primer set, which yielded the expected size of 804 bp band (Figure 4). Representative PCR analysis of the hygromycin resistant plantlets of Hwasan 101, Kowinmaster, Kospeed and Kogreen cultivars revealed the transgene integration into the genome of $\mathrm{T}_{0}$ transformant plantlets, whereas no band was observed in the non-transformed control plant (Figure 4A-C). Successful integration of the transgene gene into the genome of the PCR positive transgenic lines was further confirmed by Southern blot analysis using the genomic DNA digested with HindIII, an enzyme that has only one cutting site in the T-DNA region of the binary vector used (Figure 1). The representative Southern blot analyses of the PCR positive lines (1-6) of Hwasan 101 cultivar are shown in Figure 4D. The number of hybridizing bands reflected the number of copies of integrated transgene in the transgenic Italian ryegrass plants. Results indicated that one copy of the transgene was integrated into the genomic DNA of Italian ryegrass (Figure 5). In non-transgenic wild type plants, no hybridized band was detected. The mobilities of 
Table 3. Effect of transformation effectiveness of seven Korean Italian ryegrass cultivars.

\begin{tabular}{|l|c|c|c|c|}
\hline \multicolumn{1}{|c|}{ Cultivars } & $\begin{array}{c}\text { No. of calli } \\
\text { inoculated }^{\mathrm{a}} \text { (A) }\end{array}$ & No. of $\mathrm{Hm}^{\mathrm{R}}$ calli & $\begin{array}{c}\mathrm{Hm}^{\mathrm{R}} \text { calli showing } \\
\text { regeneration (B) }\end{array}$ & $\begin{array}{c}\text { Transformation } \\
\text { effectiveness (B/A, \%) }\end{array}$ \\
\hline Kogreen & 270 & 9 & 4 & 1.5 \\
\hline Kospeed & 270 & 11 & 6 & 2.2 \\
\hline Kowinearly & 270 & 10 & 3 & 4.1 \\
\hline Kowinmaster & 270 & 35 & 12 & 6.7 \\
\hline Hwasan 101 & 270 & 37 & 2 & 1.1 \\
\hline Hwasan 104 & 270 & 9 & 1 & 0.4 \\
\hline Kowinner & 270 & 4 & 2 & 4.4 \\
\hline
\end{tabular}

${ }^{a}$ Data were taken 5 days after Agrobacterium inoculation and means are from about 90 calli per treatment and each value is the mean of three individual experiments.

the bands differed from plant to plant, indicating independent transformation events and random integration. Although, all the tested six transgenic lines showed one copy of T-DNA insertation in to the genome of the transgenic Hwasan-101 cultivar, it is not unexpected. Similar observation has also been noticed in earlier reports on Agrobacterium-mediated transformation of other grass species, wherein majority of the transgenic plants showed one copy of T-DNA insertation in to the genome of transgenic plants (Han et al. 2005; Hu et al. 2005; Ge et al. 2006; Ge et al. 2007; Lee et al. 2008). In general, Agrobacterium-mediated transformation resulted low copy numbers of the inserted T-DNAs ranged from one to five, whereas the number of inserted T-DNAs in the host genome was comparatively high (up to eight) in particle bombardment system (Travella et al. 2005; Gao et al. 2008).

There were no apparent phenotypic and developmental differences between the wild type and transgenic plants. Therefore, the transformation method evaluated in this study allowed to generate of a large number of transgenic Italian ryegrass. It is also demonstrated that transgenic Italian ryegrass could be produced by the use of the easily
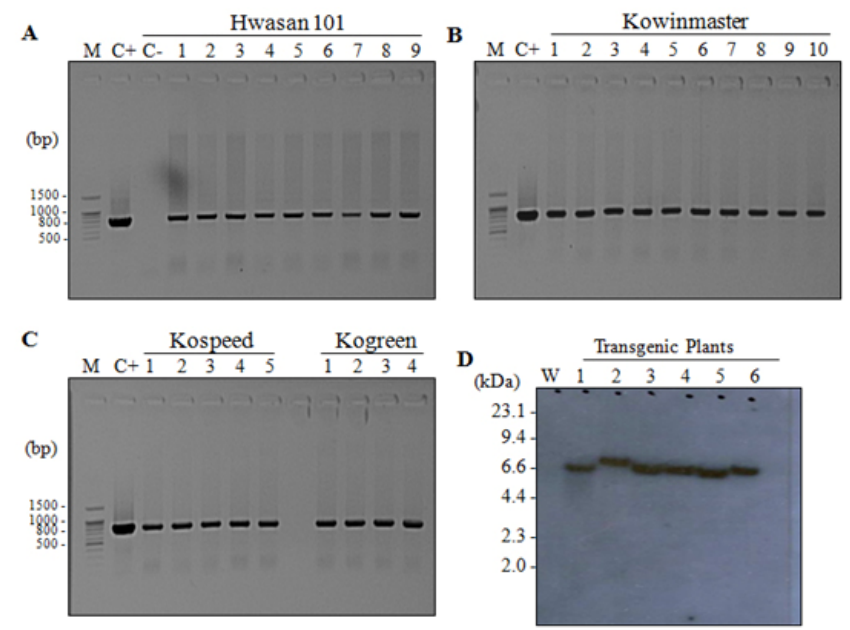

Figure 4. Molecular analyses of the putatively transformed Italian ryegrass cultivars. A-C, represents the PCR analysis, and D represents the Southern blot analysis of $\mathrm{T}_{0}$ transgenic plants. M, molecular marker; C+, pCAMBIA 1301 as a positive control; C-, nontransformed plant as a negative control. 
available pCAMBIA1301 vectors. The transformation efficiency was comparable with other Agrobacteriummediated transformation systems in grass species such as, Italian ryegrass (Bettany et al. 2003), perennial ryegrass (Wu et al. 2005) and orchardgrass (Lee et al. 2006).

In conclusion, we have evaluated the effectiveness of Agrobacterium-mediated transformation of seven Korean Italian ryegrass cultivars which revealed a highly efficient ryegrass cultivar (Hwasan 101) suitable for future studies in genetic transformation system. The transient GUS expression assay was found to be an easy and reliable way of establishing optimal conditions for transformation. In addition, the present study shows that mature seeds could be a convenient source of explants for callus induction and subsequent transformation in Italian ryegrass. This is advantageous to some grass species transformation (Ye et al. 1997; Bettany et al. 2003; Ge et al. 2007; Lee et al. 2006; Lee et al. 2007). However, the uses of immature embryos, suspension cells, protoplasts culture and uses of shoot tips as explants requires continuous growth of plant and/or explants, and the timeframe for isolation of such materials is limited.Thus the present study, emphasizes that the importance in genetic transformation if Italian ryegrass depends on the explants, cultivars and callus condition.

Therefore, the Agrobacterium-mediated transformation system might be used to develop transgenic Italian ryegrass with agronomically important genes either to increase production or to improve forage quality.

\section{ACKNOWLEDGMENTS}

We are very much thankful to Dr. Nagib Ahsan (National Institute of Crop Science, Tsukuba, Japan) for his valuable discussion and suggestions.

\section{REFERENCES}

AHSAN, N.; LEE, S.H.; LEE, D.G.; ANISUZZAMAN, M.; ALAM, M.F.; YOON, H.S.; CHOI, M.S.; YANG, J.K. and LEE, B.H. The effects of wounding type, preculture, infection method and cocultivation temperature on the Agrobacterium-mediated gene transfer in tomatoes. Annals of Applied Biology, September 2007, vol. 151, no. 3, p. 363-372.

BAI, Y. and QU, R. An evaluation of callus induction and plant regeneration in twenty-five turf-type tall fescue (Festuca arundinacea Schreb.) cultivars. Grass Forage Science, December 2000, vol. 55, no. 4, p. 326-330.

BETTANY, A.J.E.; DALTON, S.J.; TIMMS, E.; MANDERYCK, B.; DHANOA, M.S. and MORRIS, P. Agrobacterium tumefaciens-mediated transformation of Festuca arundinacea (Schreb.) and Lolium multiflorum (Lam.). Plant Cell Reports, January 2003, vol. 21, no. 5, p. 437-444.
CHAUDHURY, Ashok and QU, Rongda. Somatic embryogenesis and plant regeneration of turf-type bermudagrass: Effect of 6-benzyladenine in callus induction medium. Plant Cell, Tissue and Organ Culture, February 2000, vol. 60, no. 2, p. 113-120.

CHOI, Gi-Jun; LIM, Young-Chul; KIM, Ki-Yong; KIM, Meing-Jooung; JI, Hee-Chung; LEE, Sang-Hoon; PARK, Hyung-Soo; MOON, Chung-Sup; LEE, Uun-Sup and SEO, Sung. A cold-tolerant and medium-maturing Italian ryegrass (Lolium Multiflorum Lam.) new variety, 'Kowinmaster' J. Journal of The Korean Society of Grassland Science, September 2008, vol. 28, no. 3, p. 177184.

DALTON, S.J.; BETTANY, A.J.E.; TIMMS, E. and MORRIS, P. The effect of selection pressure on transformation frequency and copy number in transgenic plants of tall fescue (Festuca arundinacea Schreb.). Plant Science, June 1995, vol. 108, no. 1, p. 63-70.

DALTON, S.J.; BETTANY, A.J.E.; TIMMS, E. and MORRIS, P. Transgenic plants of Lolium multiflorum, Lolium perenne, Festuca arundinacea and Agrostis stolonifera by silicon carbide fibre-mediated transformation of cell suspension cultures. Plant Science, February 1998, vol. 132, no. 1, p. 31-43.

DALTON, S.J.; BETTANY, A.J.E.; TIMMS, E. and MORRIS, P. Co-transformed, diploid Lolium perenne (perennial ryegrass), Lolium multiflorum (Italian ryegrass) and Lolium temulentum (darnel) plants produced by microprojectile bombardment. Plant Cell Reports, May 1999, vol. 18, no. 9, p. 721-726.

DE KATHEN, André and JACOBSEN, Hans-Jörg. Cell competence for Agrobacterium-mediated DNA transfer in Pisum sativum L. Transgenic Research, May 1995, vol. 4, no. 3, p. 184-191.

GAO, Caixia; LONG, Danfeng; LENK, Ingo and NIELSEN, Klaus Kristian. Comparative analysis of transgenic tall fescue (Festuca arundinacea Schreb.) plants obtained by Agrobacterium-mediated transformation and particle bombardment. Plant Cell Reports, October 2008, vol. 27 , no. 10, p. 1601-1609.

GE, Yaxin; NORTON, Tina and WANG, Zeng-Yu. Transgenic zoysiagrass (Zoysia japonica) plants obtained by Agrobacterium-mediated transformation. Plant Cell Reports, August 2006, vol. 25, no. 8, p. 792-798.

GE, Yaxin; CHENG, Xiaofei; HOPKINS, Andrew and WANG, Zeng-Yu. Generation of transgenic Lolium temulentum plants by Agrobacterium tumefaciens-mediated transformation. Plant Cell Reports, June 2007, vol. 26, no. 6, p. 783-789.

HAN, Ning; CHEN, Dong; BIAN, Hong-Wu; DENG, MinJuan and ZHU, Mu-Yuan. Production of transgenic 
creeping bentgrass Agrostis stoloniferavar. palustris plants by Agrobacterium tumefaciens-mediated transformation usinghygromycin selection. Plant Cell, Tissue and Organ Culture, May 2005, vol. 81, no. 2, p. 131-138.

HIDES, D.H.; KUTE, C.A. and MARSHALL, A.H. Seed development and seed yield potential of Italian ryegrass (Lolium multiflorum Lam.) populations. Grass and Forage Science, June 1993, vol. 48, no. 2, p. 181-188.

HIEI, Yukoh; OHTA, Shozo; KOMARI, Toshihiko and KUMASIRO, Takashi. Efficient transformation of rice (Oryza sativa L.) mediated by Agrobacterium and sequence analysis of the boundaries of the T-DNA. The Plant Journal, August 1994, vol. 6, no. 2, p. 271-282.

HU, Farong; ZHANG, Lei; WANG, Xueyan; DING, Jie and WU, Dianxing. Agrobacteriumediated transformed transgenic triploid bermudagrass (Cynodon dactylon x $C$. transvaalensis) plants are highly resistant to the glufosinate herbicide liberty. Plant Cell, Tissue and Organ Culture, October 2005, vol. 83, no. 1, p. 13-19.

ISSELSTEIN, J. Influence of slight shading, sward density and nitrogen fertilization on yield and nutritive value of Lolium multiflorum Lam. Journal of Agronomy and Crop Science, June 1993, vol. 170, no. 5, p. 341-347.

JEFFERSON, R.A.; KAVANAGH, T.A. and BEVAN, M.W. GUS Fusion: $\beta$-glucuronidase as a sensitive and versatile gene fusion marker in higher plants. European Molecular Biology Organization Journal, December 1987, vol. 6, no. 13, p. 3901-3907.

$\begin{array}{llr}\text { KUMAR, K.K.; } & \text { MARUTHASALAM, } & \text { S.; } \\ \text { LOGANATHAN, } & \text { M.; } & \text { SUDHAKAR, D. and }\end{array}$ BALASUBRAMANIAN, P. An improved Agrobacteriummediated transformation protocol for recalcitrant elite indica rice cultivars. Plant Molecular Biology Reporter, March 2005, vol. 23, no. 1, p. 67-73.

LEE, Sang-Hoon; LEE, Dong-Gi; WOO, Hyun-Sook; LEE, Ki-Woon; KIM, Do-Hyun; KWAK, Sang-Soo; KIM, JinSeog; KIM, Hiegi; AHSAN, Nagib; CHOI, Myung Suk; YANG, Jae-Kyung and LEE, Byung-Hyun. Production of transgenic orchardgrass via Agrobacterium-mediated transformation of seed-derived callus tissues. Plant Science, September 2006, vol. 171, no. 3, p. 408-414.

LEE, Sang-Hoon; AHSAN, Nagib; LEE, Ki-Won; KIM, Do-Hyun; LEE, Dong-Ge; KWAK, Sang-Soo; KWON, Suk-Yoon; KIM, Tae-Hwan and LEE, Byung-Hyun. Simultaneous overexpression of both $\mathrm{Cu} \mathrm{Zn}$ superoxide dismutase and ascorbate peroxidase in transgenic tall fescue plants confers increased tolerance to a wide range of abiotic stresses. Journal of Plant Physiology, December 2007, vol. 164 , no. 12 , p. 1626-1638.

LEE, Ki-Won; AHSAN, Nagib; LEE, Sang-Hoon; LEE, Dong-Gi; KIM, Kyung-Hee; ALAM, Iftekhar; KWON,
Suk-Yoon; KIM, Jin-Seog; BACK, Kyoungwhan and LEE, Sung Sil and LEE, Byung-Hyun. Responses of MxPPO overexpressing transgenic tall fescue plants to two diphenyl-ether herbicides, oxyfluorfen and acifluorfen. Acta Physiologiae Plantarum, September 2008, vol. 30, no. 5, p. 745-754.

MURASHIGE, Toshio and SKOOG, Folke. A revise medium for rapid growth and bioassays with tobacco tissue cultures. Physiologia Plantarum, July 1962, vol. 15, no. 3, p. 473-497.

MURRAY, M.G. and THOMPSON, P.F. Rapid isolation of high molecular weight plant DNA. Nucleic Acid Research, October 1980, vol. 8, no. 19, p. 4321-4325.

NANDAKUMAR, Ragaraj; CHEN, Lin and ROGERS, Suzanne. Factors affecting the Agrobacterium-mediated transient transformation of the wetland monocot, Typha latifolia. Plant Cell, Tissue and Organ Culture, October 2004, vol. 79 , no. 1, p. 31-38.

SPANGENBERG, Germán; WANG, Zeng-Yu; WU, Xinli; NAGEL, Jutta and POTRYKUS, Ingo. Transgenic perennial ryegrass (Lolium perenne) plants from microprojectile bombardment of embryogenic suspension cells. Plant Science, June 1995, vol. 108, no. 2, p. 209-217.

TAKAHASHI, Watara; FUJIMORI, Masahiro; MIURA, Yuichi; KOMATSU, Toshinori; NISHIZAWA, Yoko; HIBI, Tadaaki and TAKAMIZO, Tadashi. Increased resistance to crown rust disease in transgenic Italian ryegrass (Lolium multiflorum Lam.) expressing the rice chitinase gene. Plant Cell Reporter, March 2005, vol. 23, no. 12 , p. 811-818.

TAKAHASHI, Wataru; OISHI, Hideki; EBINA, Masumi; TAKAMIZO, Tadashi and KOMATSU, Toshinori. Production of transgenic Italian ryegrass (Lolium multiflorum Lam.) via microprojectile bombardment of embryogenic calli. Plant Biotechnology, July 2002, vol. 19, no. 4, p. 241-249.

TRAVELLA, S.; ROSS, S.M.; HARDEN, J.; EVERETT, C.; SNAPE, J.W. and HARWOOD, W.A. A comparison of transgenic barley lines produced by particle bombardment and Agrobacterium-mediated techniques. Plant Cell Reports, March 2005, vol. 23, no. 12, p. 780-789.

URANBEY, S.; SEVIMAY, C.S.; KAYA, M.D.; IPEK, A.; SANCAK, C.; BASALMA, D.; ER, C. and ÖZCAN, S. Influence of different co-cultivation temperatures, periods and media on Agrobacterium tumefaciens-mediated gene transfer. Biologia Plantarum, March 2005, vol. 49, no. 1, p. 53-57.

WU, Yu-Ye; CHEN, Qi-Jun; CHEN, Min; CHEN, Jia and WANG, Xue-Chen. Salt-tolerant transgenic perennial ryegrass (Lolium perenne L.) obtained by Agrobacterium tumefaciens-mediated transformation of the vacuolar 
$\mathrm{Na}+/ \mathrm{H}+$ antiporter gene. Plant Science, July 2005, vol. 169, no. 1, p. 65-73.

WU, Y.Y.; CHEN, Q.J.; CUI, X.H.; CHEN, H.; CHEN, J. and WANG, X.C. Efficient regeneration and Agrobacterium-mediated stable transformation of perennial ryegrass. Russian Journal of Plant Physiology, July 2007, vol. 54, no. 4, p. 524-529.

YE, X.; WANG, Z.Y.; WU, X.; POTRYKUS, I. and SPANGENBERG, G. Transgenic Italian ryegrass (Lolium multiflorum) plants from microprojectile bombardment of embryogenic suspension cells. Plant Cell Reports, March 1997, vol. 16, no. 6, p. 379-384.

ZHAO, Junsheng; REN, Wei; ZHI, Daying; WANG, Lin and XIA, Guangmin. Arabidopsis DREB1A/CBF3 bestowed transgenic tall fescue increased tolerance to drought stress. Plant Cell Reports, September 2007, vol. 26, no. 9, p. 1521-1528. 